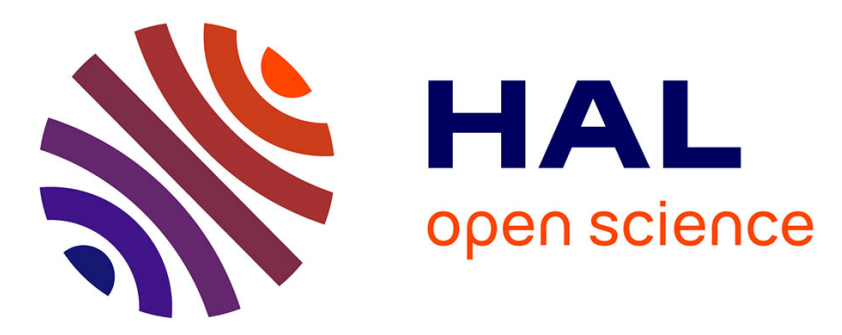

\title{
A qualitative approach to set achievable goals during the design phase of complex systems
}

\author{
Diadié Sow, Abdelhak Imoussaten, Jacky Montmain, Pierre Couturier
}

\section{To cite this version:}

Diadié Sow, Abdelhak Imoussaten, Jacky Montmain, Pierre Couturier. A qualitative approach to set achievable goals during the design phase of complex systems. IPMU, Jun 2016, Eindhoven, Netherlands. 10.1007/978-3-319-40581-0_34 . hal-01929424

\section{HAL Id: hal-01929424 \\ https://hal.science/hal-01929424}

Submitted on 21 Nov 2018

HAL is a multi-disciplinary open access archive for the deposit and dissemination of scientific research documents, whether they are published or not. The documents may come from teaching and research institutions in France or abroad, or from public or private research centers.
L'archive ouverte pluridisciplinaire HAL, est destinée au dépôt et à la diffusion de documents scientifiques de niveau recherche, publiés ou non, émanant des établissements d'enseignement et de recherche français ou étrangers, des laboratoires publics ou privés. 


\title{
A qualitative approach to set achievable goals during the design phase of complex systems
}

\author{
Diadie Sow, Abdelhak Imoussaten, Pierre Couturier, Jacky Montmain \\ Centre de Recherche LGI2P/Ecole des mines d'Alès, Site EERIE, \\ Parc scientifique G. Besse, 30035 Nîmes cedex 1, France \\ Firstname.name@mines-ales.fr
}

\begin{abstract}
.
The problem addressed in this paper is "how to set ambitious targets when improving or designing a product while these targets remain within the reach of the manufacturer". Thus, improvements to be focused on are those which both have a significant positive impact on product performance and correspond to operational changes properly under control by the manufacturer. While some approaches in the literature have already addressed each of the two issues of the improvement problem, few deal with both of them at the same time. In this paper we investigate a qualitative approach that conciliates both points of view as an optimization problem. The notion of interaction between any two objectives to be simultaneously satisfied is central in our framework. An illustrative example related to the design phase of autonomous robot is provided.
\end{abstract}

Keywords: multi criteria decision support, criteria interaction, conceptual design, performance management, qualitative reasoning.

\section{Introduction}

Competition in industry is becoming increasingly intense; therefore, in order to satisfy fluctuating demand and customers' increasing expectations, deal with the competition and remain or become market leader; industries must focus on searching for sustainable advantages. The survival of a company is heavily dependent on its capacity to identify new customer requirements and develop new products [1]. However, dealing with new products or improving existing ones in today's technology-driven market presents significant risks. Many constraints must be taken into account into the design or improvement phases [2,3]. The number of components, functions, and interactions within complex products/systems is becoming so substantial that responding to the requirements of customers, and moreover at lower cost is anything but obvious [4]. To remain successful, manufacturers must adapt to an unprecedented rate of change in their processes and practices. Such a challenge requires large forecasting capacities. Industrials must be able to produce challenging but achievable goals. The corresponding optimization problem to be solved for the industrial manufacturer is how to design new products or improve products according to customers' requirements at the limit of what is technically feasible as he is aware of his available enterprise-level skills. 
Defining achievable targets is a matter of situation awareness to relevantly manage the balance between strategic ambition and manufacturing realism. Thus, improvements to be made as a priority, i.e. targets that must be raised considerably, are those which allow both significant positive impacts on product/system performance but also correspond to actions that are derived from the expertise of the manufacturer. Industrials are thus supposed to relevantly make a prediction about the positive impact one improvement or another one might have on the global performance of the product/system but simultaneously be aware of the actions they can actually undertake with regard to their skill [5]. Forecasting the performances of a new product is far from obvious: it may be confusing to associate preferential interactions between goals and behavioral influences actions may have on these goals. This is further complicated by the qualitative characteristic of the knowledge used to do this forecasting: impacts of changes in the system/product configuration upon the expected performances cannot generally be properly quantified. Defining achievable targets is thus a risky and not deterministic process. The two aspects of the problem that this paper addresses when, improving a product or a system are:

- Assessing which performances should be improved first to maximize customer expectations [6];

- Identifying the configurations of the system that should best fulfill these expected goals [7].

Sequential management of these two steps may lead to non-convergent situations: expected goals do not necessarily match feasible ones. Identifying achievable goals necessitates a conjoint management of these two steps.

Moreover, the problem is all the more complicated because knowledge regarding actions-and-goals relationships is mostly imprecise, especially in the preliminary stage of product design [8]. Two challenges are hereafter considered when improving a complex system: at the strategic level, which changes in system outputs would bring actual improvements that would best fulfill customers' expectations, and at the operational level, how system configuration adjustments have to be carried out in order to achieve these targets. This paper is based on this semantic distinction to organize approaches in the literature and finally propose a unified framework.

These two problems have been extensively studied in the literature. Nevertheless few works integrate both of them. The first point of view focuses on defining strategic targets without actual feasibility considerations [6, 9], which may lead to focus on unachievable goals. Conversly, the second point of view focuses on the capacity to achieve specific goals while not taking into account the commitment to do it $[10,11$, 12], which may lead to focus on meaningless goals for the strategic development of the industrial manufacturer. Some attempts seem nevertheless to be aware of the necessity to deal with both aspects when improving and designing systems [13, 14]. The MAUT-like formalism in [13] is attractive, but hides the difficulty of establishing the behavioral model. In [15], we proposed to identify the coalition of criteria to be improved first using the index value defined in [6] while being the least difficult to be reached; both identifications are merged in a unique optimization problem, unlike to [7] where they are sequentially processed. This sequencing might lead to divergent 
cases where strategic targets never met feasible ones. The model in [15] avoids this misleading process, but is limited to deal with quantitative knowledge. Yet the difficulty is still compounded by the only imprecise or incomplete data and knowledge that are generally available in the conceptual phase of design. In this paper, we propose to reformulate the problem defined in [15] in a qualitative framework. Adequate qualitative operators as Sugeno integral and median operator will replace quantitative ones: Choquet integral and weighted average. Section 2 poses the problematic and the unified approach with the related optimization problem and proposes redefining the two sub problems in a qualitative framework. Section 3 proposes an illustration with a case study and discusses the results. Finally Section 4 gives some conclusions and perspectives.

\section{Modeling policy aspirations and capacity to act}

\subsection{Problem characterization and notations}

In order to study a complex system, we should characterize it by a set of parameters. For example, an autonomous robot can be characterized by several parameters: type of rolling base, size, engine type, embedded energy capacity etc. Each configuration of these parameters is an instantiation of a robot. To check if there is an improvement when changing the configuration, the decision maker has to consider the objectives that have to be achieved by the robot in terms of autonomy, reliability, mobility, cost etc. The possible configurations perform different outputs that more or less satisfy the objectives. In a general context, let a system be characterized by its ters $\gamma_{1}, \gamma_{2}, \ldots \gamma_{p}$. Let $\Gamma$ be the set of all possible values of the vector $\left(\gamma_{1}, \gamma_{2}, \ldots \gamma_{p}\right)$. A system is then defined by a configuration $\gamma \in \Gamma$. Improving a system is to make it evolve from a configuration $\gamma \in \Gamma$ to a configuration $\gamma^{\prime} \in \Gamma$ which gives a better satisfaction of the objectives that have been fixed for the system under cost constraints (money, risk, time etc.). Let us denote $N=\{1,2, \ldots n\}$, the set of criteria. The system performance is evaluated by its elementary performance measures $p_{1}, p_{2}, \ldots p_{n}$. An action $a_{j}$ is associated with each change of parameter $\gamma_{j}$. The set of actions is denoted by $A$. As there are operational constraints over the set of actions, some of them cannot be performed together: they are said to be mutually exclusive. We define an action plan denoted $a p$ as a subset of non-exclusive actions in A. We are searching among the available action plans $a p$, the ones that better improve the customer's satisfaction and that are compliant with the capacity of the manufacturer to apply them. The greater the number of individual performances to be improved, the more difficult it is to find the proper action plan.

Optimistically, one can seek for an action plan that improves all objectives associated to the system. But, it can be more relevant for the decision maker to improve a subset of criteria $I$ of $N$ that leads to reasonable satisfaction degree when the improvement is written-down to its achievability. For $I \subseteq N$, let $S(I)$ denote the degree to which improving criteria of $I$ seems achievable considering the available actions; and $W(I)$ the expected degree of satisfaction the improvement on criteria in $I$ should provide. In 
[16], we proposed an optimization problem (1) in a multi-criteria aggregation framework to identify the set of criteria $I^{*}$ that maximizes the expected degree of satisfaction under achievability constraints:

$$
\left\{\begin{array}{c}
\max _{I \subseteq \mathrm{N}} W(I) \\
\text { subject to } W(I) \leq S(I)
\end{array}\right.
$$

The problem can be seen as a multi-criteria decision making problem subject to feasibility. However, feasibility has little to do with explicit operational constraints. $S(I)$ rather assesses how much confidence there is that the actions the manufacturer intends to commit will give satisfaction. The idea is to make comparable the degree of confidence in achieving one goal and the expected degree of satisfaction this goal would provide.

In [15], $S(I)$ and $W(I)$ were defined in a quantitative setting. In this paper we propose to redefine these quantities in a qualitative setting. Indeed, the system's response to configuration changes and the decision-maker expectations are generally only imprecisely and incompletely known during the conceptual design phase. Expected benefits and achievability of targets are assessed through adequate operators in this qualitative framework.

\subsection{Qualitative characterization of the capacity to achieve a subset of criteria}

The qualitative approach involved in this section has been originally proposed in [7, $16]$ and is summarized in the following. It models the impacts that actions have on the system's performances. It covers three sub problems:

- how to characterize the impact of one parameter change on a given performance?

- how to merge the impact of several parameters' changes on a given performance?

- how to assess the overall impact a configuration may have on a set of criteria?

Let $S_{i}\left(a_{j}\right)$ denote the degree to which the action $a_{j}$ may support performance $p_{i}$. As soon as $S_{i}\left(a_{j}\right)>0$, the action $a_{j}$ contributes to the satisfaction of the criterion $i$. Let $D_{i}\left(a_{j}\right)$ be the degree to which the action $a_{j}$ may distract the performance $p_{i}$. As soon as $D_{i}\left(a_{j}\right)>0$, the action $a_{j}$ harms the criterion $i$. The qualitative action-performance relationship has then to be extended to action plans. The major difficulty is that for a given action plan $a p$ and a criterion $i$, several actions in $a p$ may affect $p_{i}$ positively and several other actions in ap may affect $p_{i}$ negatively. What is then the resulting effect of $a p$ on the performance $p_{i}$ ? To answer this question, standard multi-criteria approaches cannot be applied since both positive and negative impacts on performance level are considered here. 
Indeed, the estimation of the merged impact of an action plan naturally depends on the system behavior, as well as on the designer's/operator's decisional behavior: a pessimistic attitude (whereby a risk aversion position will focus attention on the lowest positive merged impacts of the action plan) vs. an optimistic attitude (whereby risk acceptance will focus attention on the most highly positive merged impacts). In both cases, we suppose that the merged negative impacts cannot be under rated. For example, from an optimistic point of view, the merged effect can be defined as:

$S_{i}(a p)=\max _{a \in A_{i}^{S}(a p)} S_{i}(a)$ and $D_{i}(a p)=\max _{a \in A_{i}^{D}(a p)} D_{i}(a), \quad 1$

While in a pessimistic approach:

$S_{i}(a p)=\min _{a \in A_{i}^{S}(a p)} S_{i}(a)$ and $D_{i}(a p)=\max _{a \in A_{i}^{D}(a p)} D_{i}(a)$

where $A_{i}^{S}(a p)=\left\{\mathrm{a} \in\right.$ ap $\left.: S_{i}(a)>0\right\}$ and $A_{i}^{D}(a p)=\left\{\mathrm{a} \in\right.$ ap $\left.: D_{i}(a)>0\right\}$.

Then, the degree to which an action plan may affect a subset of criteria is yet to be defined. Let $I \subseteq N$ be a subset of criteria and $a p$ an action plan. The resulting degree to which ap should contribute to the improvement of $I$ while not deteriorating the other criteria in $N \backslash I$ can be assessed, from a pessimistic point of view by:

$S_{I}(a p)=\left\{\begin{array}{c}\min _{i \in I} S_{i}(a p) \text { if } \forall j \in N \backslash I\left[S_{j}(a p)>D_{j}(a p) \text { or } A_{j}^{D}(a p)=\emptyset\right], \\ 0 \text { otherwise }\end{array}\right.$

(respectively $\left\{\begin{array}{c}\max _{i \in I} S_{i}(a p) \text { if } \forall j \in N \backslash I\left[S_{j}(a p)>D_{j}(a p) \text { or } A_{j}^{D}(a p)=\emptyset\right] \text { from } \\ 0 \text { otherwise }\end{array}\right.$

an optimistic point of view).

More precisely $S_{I}(a p)>0$ if any criterion in $I$ is improved by $a p$, whereas no criterion in $N \backslash I$ is distracted ${ }^{2}$.

Finally, $\max _{a p} S_{I}(a p)$ characterizes the highest degree to which criteria in $I$ can be expected to be improved considering all possible action plans. Hence, the quantity $s(I)=\max _{a p} S_{I}(a p)$ is considered here as the assessment of the capacity to achieve improvement of $I$.

${ }^{1}$ Considering $D_{i}(a p)=\min _{a \in A_{i}^{D}(a p)} D_{i}(a)$, should be too permissive.

${ }^{2}$ In fact we believe that only the pessimistic point of view is a reasonable attitude to compute $s_{I}(a p)$ since a conjunctive aggregation is necessary in order to guarantee that all criteria of I are expected to be improved. 


\subsection{Qualitative characterization of the commitment to achieve a subset of criteria}

In this sub-section, we are interested in determining the criteria that should be improved first to satisfy as much as possible the decision-maker expectations. For this purpose, we build a value function $w_{p}$ defined on the set of all the criteria subsets $I$ of $N$, and that estimates the expected overall satisfaction the improvement of criteria in $I$ would provide, knowing that the initial performances are given by the vector of performances $p^{0}=\left(p_{1}^{0}, p_{2}^{0}, \ldots, p_{n}^{0}\right)$. In our qualitative multi-criteria framework, the overall satisfaction related to any vector of partial performances $\left(p_{1}, p_{2}, \ldots, p_{n}\right)$ is modeled as the qualitative aggregation of the $p_{i}$ 's performance on the $i^{\text {th }}$ criterion by the Sugeno integral. This operator both allows modeling the importance of criteria but also the preferential interactions among them. Let us start by recalling some notations concerning the Sugeno integral.

Let $L$ be an ordered qualitative scale with $1_{L}$ its highest value and $0_{L}$ its lowest value. A function $\mu: 2^{N} \rightarrow L$ is called a fuzzy measure if it satisfies the following conditions:

1. $\mu(\varnothing)=0_{L}$

2. $\mu(N)=1_{L}$

3. $\mu$ is monotonic non decreasing for inclusion, i.e., for any $A, B \subseteq N A \subseteq B \Rightarrow$ $\mu(A) \leq \mu(B)$.

The monotonicity of $\mu$ means that the weight of a subset of criteria cannot decrease when new criteria are added to it (see $[9,10]$ for further details).

Let $\mu$ be a fuzzy measure on $\mathrm{N}$ taking values in the scale $L$. Let consider a function $f: N \rightarrow L$, then the Sugeno integral of $f$ with respect to $\mu$, denoted $S_{\mu}(f)$ is given by:

$$
S_{\mu}(f)=\max _{1 \leq i \leq n}\left(\min \left(f_{\sigma(i)}, \mu\left(A_{\sigma(i)}\right)\right),\right.
$$

where $\sigma$ is a permutation on $N$ such that $f_{\sigma(1)} \leq f_{\sigma(2)} \leq \cdots f_{\sigma(n)}$, and $A_{\sigma(i)}=$ $\{\sigma(i), \sigma(i+1), \ldots \sigma(n)\}$.

This integral is monotone, and obviously presents a compromise behavior. It searches the importance exceeding a certain level, and then performs a compromise deal between the selected values. Another point of view is to see this combination as the disjunction of conjunctions. All the criteria, their interactions and their importance, are taken into account to assess the aggregated score of a given vector of elementary ratings $[17,18,19]$.

Let us consider that the overall performance of the system is evaluated from criteria performances using a Sugeno integral operator with respect to the fuzzy measure $\mu$ : $S_{\mu}(p)=\max _{1 \leq i \leq n}\left(\min \left(p_{\sigma(i)}, \mu\left(A_{\sigma(i)}\right)\right)\right.$ where $p_{i}$ is the $i^{\text {th }}$ performance with a value in the same ordinal scale $L=\left\{0_{L}, \ldots, 1_{L}\right\}$ as the capacity $\mu$. By considering the set of criteria $I$ and the initial vector of performances $p^{0}$, several vectors of performances $p^{k}$ are possible improvements on $I$. If $p^{0}=\left(p_{1}^{0}, p_{2}^{0}, \ldots, p_{n}^{0}\right)$, then any $p^{k}=$ 
$\left(p_{1}^{k}, p_{2}^{k}, \ldots, p_{n}^{k}\right)$ such that $\forall i \in I, p_{i}^{k}>p_{\mathrm{i}}^{0}$ is a possible improvement. Let us note Improvt $_{p^{0}}$ the set of all these vectors such that $p^{k}$ is obtained from $p^{k-1}$ by increasing each $p_{i}^{k-1}$ one step up (steps are the levels of $L$ ) for all the criteria in $I$. In other words, similarly to [6], only improvements obtained by progressing from $p^{0}$ to $1_{I}$ along the diagonal of the $|I|$-cube are considered (where $|I|$ denotes the cardinal of $I$ ) in order to be sure to improve all criteria in $I$. To each expected improvement $p^{k}$ is associated its overall performance $S_{\mu}\left(p^{k}\right)$. Then, the expected overall performance in this qualitative framework of performance can be assessed by the median of the $S_{\mu}\left(p^{k}\right)^{\prime} s$. The median provides how worth it is improving criteria on $I$ (the median is an associative qualitative compensatory aggregation operator [21]):

$$
w_{p^{0}}(I)=\operatorname{med}\left(S_{\mu}\left(p^{0}\right), S_{\mu}\left(p^{1}\right), \ldots S_{\mu}\left(p^{\max }\right)\right), \text { where } p^{\max }=\left(1_{I}, p_{N \backslash I}^{0}\right) .
$$

Note that the cardinal number of Improvt $p^{0}$ may be odd or even. Since in the last case the median consists of finding a value between the two middle points, such a choice depends on the decision maker's attitude. A pessimistic attitude would take first middle point as the median, while an optimistic one would take the second point.

\subsection{Optimization problem in the qualitative setting}

Note that by construction, $I \subseteq I^{\prime} \Rightarrow s_{I}(a p) \geq s_{I^{\prime}}(a p), \forall a p$, and therefore $s(I) \geq$ $\mathrm{s}\left(\mathrm{I}^{\prime}\right)$. In the other hand, $I \subseteq I^{\prime} \Longrightarrow w_{p^{0}}(I) \leq w_{p^{0}}\left(I^{\prime}\right)$ for a given initial performance vector $p^{0}$. Hence these two functions are respectively non-increasing and nondecreasing with respect to $I$ (with respect to the inclusion relationship), and so coincide at an optimal given $I^{*}$ solution of the optimization problem (1). Hence, the problem of searching the subset of criteria that are both profitable and achievable is equivalent to the optimization problem (1) with $s(I)$ and $w_{p^{0}}(I)$ as arguments. However precautions are necessary to properly process the inequality constraint of problem (1). In the case where these functions take their values in different ordered qualitative scales, a third ordered qualitative scale can be introduced where values have the semantic of satisfaction degree or of possibility degree in order to draw the comparison of the inequality in (1).

Solving this problem may be extremely hard with $2^{|A P|}$ action plans and $2^{|N|}$ subsets of criteria to search. The first thorny exponential problem comes from the computation of $s(I)$ : heuristics have already been introduced in a branch and bound algorithm in [7] to compute $s(I)$ in a reasonable time. Further heuristics are needed to solve (1) while computing the minimum of $s(I)$ 's values; they will be addressed in our future works. We give here just an overview of two heuristics. The first heuristic will be based on the inverse monotonicity of $s(I)$ and $w_{p}(I)\left(I \subseteq I^{\prime} \Rightarrow s(I) \geq \mathrm{s}\left(\mathrm{I}^{\prime}\right)\right.$ and, $I \subseteq$ $\left.I^{\prime} \Rightarrow w_{p^{0}}(I) \leq w_{p^{0}}\left(I^{\prime}\right)\right)$; a second heuristic will introduce lower and upper bounds 
for $s(I)$. In the following study case $|N|$ and $|A P|$ are small enough to perform exhaustively all the required computations.

\section{Design Application}

The following example has no validation ambition but aims at illustrating the proposed approach. The robotic challenge Robafis is organized annually by the French association of Systems Engineering AFIS to promote Systems Engineering practice in engineers' schools ${ }^{3}$. The scope of the challenge is for instance (Robafis_2013) to build an autonomous mobile robot able to compete with other robots and using some provided and imposed materials. Each robot is limited to a $0.3^{3} \mathrm{~m}^{3}$ cube and has to achieve the following mission as quickly as possible: to grasp and transport some various colored spheres between several stock devices spread over a plan playground. Some dark lines are drawn on the ground to guide the robot between stock devices. The autonomous robot was broken down into four sub-systems: a gripper device, sensors equipment, a rolling base, a control device. The programmable control device type is also imposed to the competitors. The physical alternatives (the possible robot configurations) depend on the design options and on the skills of each competitor. The preference model depends on the strategy followed by each competitor. The solution principles are resumed in Table 1. There are three principles for designing the gripper device, three for the rolling base and two for the sensors equipment. Thus, there are 18 actions plans to be compared, corresponding to the $3 \times 3 \times 2$ admissible configurations.

In this example an action is the choice of one element of the configuration, and an action plan is a configuration.

\subsection{Data of the application}

Four criteria are considered to decide between configurations: the sparsity of used components $(\mathrm{Cr} 1)$, the robot speed capacity $(\mathrm{Cr} 2)$, the reliability of the robot $(\mathrm{Cr} 3)$, and the maintainability of the robot $(\mathrm{Cr} 4)$. Taking into account the competition rules, Table 2 provides an example of competitors' preferences between the criteria modeled by a qualitative capacity function $\mu: 2^{N} \rightarrow L$ where $\mathrm{N}=\{1,2,3,4\}$, and $\mathrm{L}=$ $\left\{0, a, b, c, d, e=1_{L}\right\} ; 0$ means: not important at all and e means very important. Table 3 presents, for each of the four criteria, the positive impact (denoted by "+") or the negative impact (denoted by "-.") of each elementary technical choice on the satisfaction level of each criteria. Furthermore a confidence degree in the fulfillment of such an impact is defined on the same qualitative scale $\mathrm{L}$.

\footnotetext{
${ }^{3}$ (http://www.robafis.fr/RobAFIS/Bienvenue.html).
} 
Table 1. Solution principles

\begin{tabular}{|l|l|l|}
\hline \multicolumn{1}{|c|}{ Gripper device } & \multicolumn{1}{|c|}{ Rolling base } & \multicolumn{1}{c|}{ Sensors equipment } \\
\hline $\begin{array}{l}\text { G1: Fork (taking the } \\
\text { sphere from below) }\end{array}$ & $\begin{array}{l}\text { R1: Four wheels } \\
\text { rolling base }\end{array}$ & $\begin{array}{l}\text { S1: two color sensors for following the } \\
\text { dark lines, one light sensor for recog- } \\
\text { nizing the sphere color }\end{array}$ \\
\hline $\begin{array}{l}\text { G2: Lateral gripper } \\
\text { (pinching laterally } \\
\text { the sphere) }\end{array}$ & $\begin{array}{l}\text { R2: Two wheel } \\
\text { drive and one free } \\
\text { wheel rolling base }\end{array}$ & $\begin{array}{l}\text { S2: one color sensor for following the } \\
\text { dark line, one color sensor for recog- } \\
\text { nizing the sphere color }\end{array}$ \\
\hline $\begin{array}{l}\text { G3: Grapnel (taking } \\
\text { over the sphere) }\end{array}$ & $\begin{array}{l}\text { R3: rolling base } \\
\text { with tracks }\end{array}$ & \\
\hline
\end{tabular}

Table 2. Competitors' Preferences: the qualitative capacity function values $\mu(I)$

\begin{tabular}{|c|c|c|c|c|c|c|c|}
\hline $\mathrm{I}$ & $\mu(I)$ & $\mathrm{I}$ & $\mu(I)$ & $\mathrm{I}$ & $\mu(I)$ & $\mathrm{I}$ & $\mu(I)$ \\
\hline$\varnothing$ & 0 & $\{\mathrm{C} 4\}$ & $\mathrm{a}$ & $\{\mathrm{C} 1, \mathrm{C} 3\}$ & $\mathrm{b}$ & $\{\mathrm{C} 1, \mathrm{C} 3, \mathrm{C} 4\}$ & $\mathrm{d}$ \\
\hline$\{\mathrm{C} 1\}$ & $\mathrm{a}$ & $\{\mathrm{C} 1, \mathrm{C} 4\}$ & $\mathrm{b}$ & $(\mathrm{C} 2, \mathrm{C} 3)$ & $\mathrm{d}$ & $\{\mathrm{C} 2, \mathrm{C} 3, \mathrm{C} 4\}$ & $\mathrm{d}$ \\
\hline$\{\mathrm{C} 2\}$ & $\mathrm{a}$ & $\{\mathrm{C} 2, \mathrm{C} 4\}$ & $\mathrm{c}$ & $(\mathrm{C} 1, \mathrm{C} 2, \mathrm{C} 3)$ & $\mathrm{e}$ & $\{\mathrm{C} 1, \mathrm{C} 2, \mathrm{C} 3, \mathrm{C} 4\}$ & $\mathrm{e}$ \\
\hline$\{\mathrm{C} 1, \mathrm{C} 2\}$ & $\mathrm{b}$ & $\{\mathrm{C} 1, \mathrm{C} 2, \mathrm{C} 4\}$ & $\mathrm{d}$ & $\{\mathrm{C} 3\}$ & $\mathrm{b}$ & $\{\mathrm{C} 3, \mathrm{C} 4\}$ & $\mathrm{b}$ \\
\hline
\end{tabular}

Table3. Impacts of configurations

\begin{tabular}{|l|c|c|c|c|}
\cline { 2 - 5 } \multicolumn{1}{c|}{} & Number of Pieces & Speed & Reliability & Maintainability \\
\cline { 2 - 5 } \multicolumn{1}{c|}{} & Cr1 & Cr2 & Cr3 & Cr4 \\
\hline G1: fork & $+\mathrm{e}$ & $-\mathrm{a}$ & $-\mathrm{b}$ & $+\mathrm{e}$ \\
\hline G2: gripper & $-\mathrm{b}$ & $-\mathrm{a}$ & $+\mathrm{d}$ & $-\mathrm{a}$ \\
\hline G3: graspel & $-\mathrm{d}$ & $-\mathrm{a}$ & $+\mathrm{c}$ & $-\mathrm{d}$ \\
\hline R1: 4wheels & $+\mathrm{e}$ & $-\mathrm{c}$ & $-\mathrm{d}$ & $+\mathrm{c}$ \\
\hline R2: 3 wheels & $-\mathrm{c}$ & $+\mathrm{d}$ & $+\mathrm{c}$ & $-\mathrm{b}$ \\
\hline R3: trackers & $-\mathrm{d}$ & $+\mathrm{c}$ & $-\mathrm{c}$ & $-\mathrm{d}$ \\
\hline S1: $2+1$ & $-\mathrm{c}$ & $+\mathrm{e}$ & $+\mathrm{c}$ & $-\mathrm{c}$ \\
\hline S2: $1+1$ & $+\mathrm{b}$ & $-\mathrm{d}$ & $-\mathrm{c}$ & $+\mathrm{c}$ \\
\hline
\end{tabular}

It must be emphasized here that the approach differs from just aggregating subcriteria of multiple options and choosing the best one since actions may have positive or negative impacts on the criteria (it is a bipolar problem) and that Table 3 results from an analysis of a behavior model of the robot and describes the confidence the designers have in the impacts the actions may have on each partial performance.

\subsection{Computation of $w_{p^{i}}$}

Let's consider some given initial performance vectors: $p^{0}=\left(\begin{array}{llll}0 & 0 & 0 & 0\end{array}\right), \mathrm{p}^{0_{1}}=$ $(0 \mathrm{a} 0 \mathrm{a}), \mathrm{p}^{0_{2}}=(0 \mathrm{~d} \mathrm{~b} \mathrm{c})$. The Sugeno integral for each of these initial performance 
vectors are respectively: $S_{\mu}\left(\mathrm{p}^{0}\right)=0, S_{\mu}\left(\mathrm{p}^{0_{1}}\right)=\mathrm{a}, S_{\mu}\left(\mathrm{p}^{0_{2}}\right)=\mathrm{d}$ with respect to the capacity defined in table 2 . Hence, the values of the $w_{p^{0_{i}}}$ for each initial performance vectors are given in the Table 4:

Table 4. $w_{p^{0_{i}}}(I)$ values for different initial performances $p^{0_{i}}$

\begin{tabular}{|c|c|c|c|c|c|c|c|c|}
\hline$w_{p^{i}} / I$ & $\{1\}$ & $\{1,2\}$ & $\{1,3\}$ & $\{1,4\}$ & $\{1,2,3\}$ & $\{1,2,4\}$ & $\{1,3,4\}$ & $\{1,2,3,4\}$ \\
\hline$w_{p^{0}}(I)$ & $\mathrm{a}$ & $\mathrm{b}$ & $\mathrm{b}$ & $\mathrm{b}$ & $\mathrm{c}$ & $\mathrm{c}$ & $\mathrm{c}$ & $\mathrm{c}$ \\
\hline$w_{p^{0_{1}}}(I)$ & $\mathrm{a}$ & $\mathrm{b}$ & $\mathrm{b}$ & $\mathrm{b}$ & $\mathrm{c}$ & $\mathrm{c}$ & $\mathrm{c}$ & $\mathrm{c}$ \\
\hline$w_{p^{0_{2}}}(\mathrm{I})$ & $\mathrm{c}$ & $\mathrm{c}$ & $\mathrm{d}$ & $\mathrm{c}$ & $\mathrm{d}$ & $\mathrm{c}$ & $\mathrm{d}$ & $\mathrm{d}$ \\
\hline \multicolumn{7}{|c|}{} \\
\hline$w_{p^{i}} / I$ & $\{2\}$ & $\{2,3\}$ & $\{2,4\}$ & $\{2,3,4\}$ & $\{3\}$ & $\{3,4\}$ & $\{4\}$ & \\
\hline$w_{p^{0}}(I)$ & $\mathrm{a}$ & $\mathrm{c}$ & $\mathrm{c}$ & $\mathrm{c}$ & $\mathrm{b}$ & $\mathrm{b}$ & $\mathrm{a}$ & \\
\hline$w_{p^{0_{1}}}(I)$ & $\mathrm{a}$ & $\mathrm{c}$ & $\mathrm{c}$ & $\mathrm{c}$ & $\mathrm{b}$ & $\mathrm{b}$ & $\mathrm{a}$ & \\
\hline$w_{p^{0_{2}}}(I)$ & $\mathrm{c}$ & $\mathrm{d}$ & $\mathrm{c}$ & $\mathrm{d}$ & $\mathrm{d}$ & $\mathrm{d}$ & $\mathrm{c}$ & \\
\hline
\end{tabular}

It can be easily checked in Table 4 that $I \subseteq I^{\prime} \Longrightarrow w_{p^{0_{i}}}(I) \leq w_{p^{0_{i}}}\left(I^{\prime}\right)$ and $w_{p^{0_{i}}}$ depends on the initial performance: the higher the initial global performance value $S_{\mu}\left(p^{0_{i}}\right)$, the higher $w_{p^{0_{i}}}(I)$. As the configuration to be selected is the first design choice, we assume that the initial performance vector is the null vector $\left(\mathrm{p}^{0}\right)$. Then, with such an initial vector, the Sugeno integral properties, the median operator and the ordinal scale $L$ imply that $w_{\mathrm{p}^{0}}$ cannot exceed the value $c$.

\subsection{Computation of $s(I)$}

The values of the $s(I)^{\prime} s$ for each subset of criteria $I$ are computed with an optimistic attitude (see section 2.2) and are given in Table 5:

Table 5. $s(I)$ values

\begin{tabular}{|c|c|c|c|c|c|c|c|c|}
\hline $\mathrm{s} / \mathrm{I}$ & $\{1\}$ & $\{2\}$ & $\{1,2\}$ & $\{3\}$ & $\{1,3\}$ & $\{2,3\}$ & $\{1,2,3\}$ & $\{4\}$ \\
\hline$s(I)$ & $\mathrm{e}$ & $\mathrm{e}$ & $\mathrm{e}$ & $\mathrm{d}$ & $\mathrm{d}$ & $\mathrm{d}$ & $\mathrm{d}$ & $\mathrm{e}$ \\
\hline & & & & & & & & \\
\hline s / I & $\{1,4\}$ & $\{2,4\}$ & $\{1,2,4\}$ & $\{3,4\}$ & $\{1,3,4\}$ & $\{2,3,4\}$ & $\{1,2,3,4\}$ & \\
\hline$s(I)$ & $\mathrm{e}$ & $\mathrm{e}$ & $\mathrm{e}$ & $\mathrm{c}$ & $\mathrm{c}$ & $\mathrm{c}$ & $\mathrm{c}$ & \\
\hline
\end{tabular}

Considering the initial performance $\mathrm{p}^{0}, s(I)$ takes its values on $\{c, d, e\}$. The only valid coalitions $I^{*}$ that satisfy the inequality constraint of (1) are the coalition $\{2,4\}$ and $\{1,2,4\}$ which happen to maximize, in this particular case both $s(I)$ and $w_{p_{1}^{0}}(I)$. Thus, according to the competitors' preference model defined in Table 4, the best strategy to follow is to build a robot with high speed and easily maintainable. Consid- 
ering Table 3, the three configurations that improve $I^{*}$ and do not degrade the performance on $N / I^{*}$ are : $\mathrm{a}_{1}=\left\{\mathrm{G}_{1}, \mathrm{R}_{1}, \mathrm{~S}_{2}\right\}, \mathrm{a}_{2}=\left\{\mathrm{G}_{1}, \mathrm{R}_{2}, \mathrm{~S}_{2}\right\}$ and $\mathrm{a}_{3}=\left\{\mathrm{G}_{1}, \mathrm{R}_{3}, \mathrm{~S}_{2}\right\}$. The three rolling bases are acceptable at this stage of the design. A sensibility analysis has to be undergone in order to consolidate this configurations choice. Such analysis should be included in a wider risk analysis that should be the scope of further research work.

\section{Conclusion}

Dealing with new products or improving existing ones in today's technology-driven markets present important risks. In the case of complex industrial systems, the number of constraints and goals rapidly becomes inextricable. Manufacturers are faced with an unprecedented rate of changes in their processes and practices. This challenge requires large forecasting capacities to produce challenging but achievable goals. In [15], we have proposed a model in a quantitative framework of performance to better manage the balance between strategic ambition and manufacturing realism. Nevertheless, the forecasts are yet compounded by the only imprecise or incomplete knowledge generally available in the conceptual phase of design. In this paper, we have proposed to reformulate the problem defined in [15] in a qualitative framework. This qualitative approach allows lifting the constraint encountered in [15]. It allows qualitative reasoning with a gradient like approach, which seems more consistent with the available knowledge during design phases. The case study of a design autonomous robot shows the necessity of considering simultaneously know-how and ambition in design project to set achievable goals. Identifying achievable goals necessitates a conjoint management of feasibility and ambition in their definition contrarily to [7] where they were sequentially managed. In future works, we will propose another point of view to this conjoint control issue. The idea is to integrate the capacity $s(I)$ in the computation of $w_{I}$ in such a way that improvements are all the less credible than they require high level of know-how whereas improvements are all considered equally probable in the models of [7] and [15].

\section{References}

1. Shen, X.X., Tan, K.C, Xie, M. (2000). An integrated approach to Innovative Product Development using Kano's model and QFD, European Journal of Innovation Management, 3(2): 91-99

2. Baykasoglu, A., Oztas, A., Ozbay, E. (2002), Prediction and multi-objective optimization of high strength concrete parameters via soft computing approaches, Expert Syst. Appl. 36: 6145-6155

3. Ng, K.W. (2006). A critical analysis of current engineering design methodologies from a decision making perspective, In Intelligent Production Machines and Systems, edited by DT Pham, EE Eldukhri, and AJ Soroka, Elsevier Science Ltd. 
4. Moulianitis, V.C., Aspragathos, N.A., Dentsoras, A.J. (2004). A model for concept evaluation in design-an application to mechatronics design of robot grippers, Mechatronics, 14 (6): 599-622.

5. Hauser, JR, Clausing, D. (1988). The house of quality, In Harvard Business Review, MayJune, 63-73.

6. Labreuche, C. (2004). Determination of the criteria to be improved first in order to improve as much as possible the overall evaluation, IPMU, Perugia, Italy.

7. Montmain, J., Labreuche, C., Imoussaten, A., Trousset, F. (2015). Multi-criteria improvement of complex systems, Information Sciences, 291:61-84.

8. Antonsson, E. K., Otto, K. N. (1995). Imprecision in Engineering Design, ASME Journal of Mechanical Design (Invited paper).

9. Keeney, R. and Raiffa, H. (1976). Decisions with Multiple Objectives: Preferences and Value Tradeoffs, New York: Wiley.

10. Giorgini, P., Mylopoulos, J., Nicchiarelli, E. and Sebastiani, R. (2002). Reasoning with Goal Models, $21^{\text {st }}$ Int. Conf. on Conceptual Modeling (ER02), Tampere, Finland, 167-181.

11. Felix, R. (1994). Relationships between goals in multiple attribute decision making. Fuzzy sets\&systems, 67:47-52.

12. Montmain, J., Clivillé, V., Berrah, L., Mauris, G. (2010). Preference and causal fuzzy models for manager's decision aiding in industrial performance improvement, FUZZ-IEEE 2010, Barcelona, Spain.

13. Clivillé, V., Corrente, S., Greco, S., Rizzon, B. (2015), Feasible Optimization, MCDA2015, Annecy,

http://www.polytech.univsavoie.fr/fileadmin/polytech_autres_sites/sites/mcda2015/doc/ses sion/MCDA81_session5_1.pdf

14. Fleurey, F., Delhen, V., Bencomo, N., Morin, B. and Jézéquel, J.M. (2008). Modeling and validating dynamic adaptation, $3^{\text {rd }}$ Int. workshop on Models @ Runtime (MRT'08), MoDELS'08, Toulouse, France.

15. Sow, D., Imoussaten, A., Couturier, P., Montmain, J. (2015). Between policy aspirations and capacity to act: how designing achievable goals, $L F A$, Poitiers, France.

16. Imoussaten, A. (2011). Modélisation et pilotage de la phase de délibération dans une décision collective-vers le management d'activités à risques, thèse de Doctorat de l'Ecole des mines de Paris.

17. De Campos, L., Lamata, M., Moral, S. (1991). A unified approach to define fuzzy integrals, Fuzzy Sets and Systems, 39(1): 75-90.

18. Dubois, D., Marichal, J-L, Prade, H., Roubens, M., Sabbadin,R. (2001). The use of the discrete Sugeno integral in decision-making: a survey, International Journal of Uncertainty, Fuzziness and Knowledge-Based Systems, 9(5) : 539-561.

19. Grabisch, M. (2003). The symmetric Sugeno integral, Fuzzy sets and systems, 139(3): 473490.

20. Dubois, D, Grabish, M, Prade, H, Smets, P. (2001). Using the transferable belief model and a qualitative possibility theory approach on an illustrative example: The assessment of the value of a candidate, International Journal of Intelligent Systems, 16:1245-1272

21. Arif, M. (2006). AWFO (un opérateur d'agrégation) pour la reconnaissance des formes. 15 e congrès francophone de Reconnaissance des Formes et Intelligence Artificielle.

22. Mouelhi, O., Couturier, P., Redarce, T. (2009). A hybrid search algorithm for multi-criteria optimization and evaluation in mechatronic products design, Advanced intelligent Mechatronics, Singapore 